\title{
SISTEM INFORMASI PENERIMAAN KARYAWAN BARU BERBASIS WEBSITE PADA PT. SAMYANG TOUR \& TRAVEL JAKARTA
}

\author{
Windi Prastyo ${ }^{1}$, Asri Wahyuni ${ }^{2}$ \\ Sekolah Tinggi Manajemen Informatika \& Komputer Nusa Mandiri/Sistem Informasi \\ Jalan Damai No. 8 Warung Jati Barat (Margasatwa), 021-78839513 \\ e-mail: prastyowindi@gmail.com, asri.awx@nusamandiri.ac.id
}

\begin{abstract}
Abstrak
Sistem yang digunakan pada PT. Samyang Tour \& Travel Jakarta masih bersifat pembukuan sehingga berdampak negatif khususnya pada penerimaan karyawan baru, yang membutuhkan waktu lebih dalam penerimaan karyawan serta data yang disajikan tidak akurat. Metode yang digunakan dalam penelitian ini menggunakan metode waterfall. Tahap metode penelitian yang dilakukan adalah Analisis Kebutuhan, Desain, Pengkodean, Pengujian, Implementasi, dan Support. Hasil dari analisa menyatakan bahwa sistem yang diterapkan efektif dalam proses penerimaan karyawan. Data yang disajikan pun akurat dalam mengelola data. Rancangan sistem yang dibuat bersifat komputerisasi dengan MySQL dan PhpMyAdmin sebagai basis data, serta Dreamweaver sebagai desain prototype interface untuk Sistem Informasi Penerimaan Karyawan Baru Pada PT.Samyang Tour \& Travel Berbasis Website ini.
\end{abstract}

Kata kunci: Sistem Informasi, Penerimaan Karyawan Baru, PT.Samyang Tour \& Travel, Website.

\begin{abstract}
The system used at PT. Samyang Tour \& Travel Jakarta is still bookkeeping so it has a negative impact, especially on the recruitment of new employees, which requires more time in hiring employees and the data presented is inaccurate. The method used in this study uses the waterfall method. The research method phase that was carried out was Requirement Analysis, Design, Coding, Testing, Implementation, and Support. The results of the analysis state that the system implemented is effective in the process of hiring employees. The data presented is also accurate in managing data. The system design is computerized with MYSQL and PhPMyAdmin as the database, and Dreamweaver as a prototype interface design for the New Employee Admission Information System at PT. Samyang Tour \& Travel Based on this Website.
\end{abstract}

Keywords: Information Systems, Acceptance of New Employees, PT. Samyang Tour \& Travel, Website

\section{PENDAHULUAN}

PT. Samyang Tour \& Travel Membutuhkan karyawan untuk mengelola manajemen perusahaan. Oleh karena itu, seorang staf HRD (Human Resource Development) harus mempunyai informasi-informasi tentang pelamar kerja yang masuk ke perusahaan agar karyawan yang diterima bekerja sesuai dengan kriteria yang dibutuhkan.

Karyawan atau "Sumber Daya Manusia (SDM) merupakan salah satu aset berharga yang dimiliki oleh setiap perusahaan" [1]. Aset-aset lain yang dimiliki oleh perusahaan seperti modal, bangunan, mesin, peralatan kantor, persediaan barang, dan lainnya, namun hanya karyawan lah yang dapat bernapas, berpikir, merasa, dan berperilaku. Keunikan ini jika memiliki kualitas yang baik dan dilibatkan dalam aktifitas usaha akan memberikan sumbangan yang besar bagi kemajuan perusahaan. Pada umumnya "perusahaan kesulitan dalam mendapatkan karyawan yang baik dan berkualitas untuk posisi jabatan yang dibutuhkan" [2]. "Untuk menentukan calon pegawai yang memenuhi kriteria maka dibutuhkan rekomendasi yang tepat"[3]. "Proses rekrutmen adalah sebuah proses yang menghasilkan sejumlah pelamar yang memiliki kualifikasi untuk pekerjaan disuatu perusahaan" [4].

Pada sistem yang berjalan saat ini, staf HRD membutuhkan waktu yang lama dalam mengumpulkan informasi-informasi tentang pelamar kerja yang masuk, sehingga proses penerimaan pun tidak benar-benar memiliki objektitivitas yang tinggi karena waktu dan tenaga sudah terbuang pada saat pengumpulan informasi. Informasi lowongan kerja yang dibuka perusahaan juga penting sekali masyarakat yang sedang 
membutuhkan pekerjaan, dimana masyarakat dapat mengetahui informasi lowongan dengan cepat, tidak menyia-yiakan waktu dan tenaga. "Beberapa perusahaan besar maupun kecil menyediakan informasi lowongan kerja melalui media cetak seperti koran"[5]. Keadaan yang sekarang diamati bahwa banyak pelamar kerja yang datang juga ada yang berasal dari luar daerah. Dalam mencari informasi lowongan kerja, "Biasanya pelamar masih menggunakan cara-cara konvensional, yaitu dengan mendatangi perusahaan untuk melihat papan pengumuman dan menghasilkan tumpukan berkas yang banyak"[6].

Untuk mengatasi permasalahan tersebut dan untuk meningkatkan kinerja dalam melayani para pelamar kerja, maka dibutuhkan sistem penerimaan karyawan baru dengan menggunakan teknologi komputer, yaitu berbasis website. Hal tersebut menjadi dasar untuk memudahkan pelamar kerja dalam melakukan pengiriman berkas lamaran dan mengikuti tes penerimaan masuk ke perusahaan secara online serta dapat langsung mengetahui hasil dari lamaran yang telah dikirim

\subsection{Identifikasi Masalah}

a. Sistem penerimaan karyawan baru pada PT. Samyang Tour \& Travel masih sistem manual pencacatan dan penerimaannya.

b. Pengelolaan data untuk admin dalam penyimpanan data pelamar kerja masih kurang rapi.

c. Kurang efisien waktu dalam penerimaan karyawan.

\subsection{Perumusan Masalah}

a. Bagaimana sistem informasi penerimaan karyawan baru berbasis website?

b. Bagaimana perancangan untuk pengolahan data dalam penyimpanan data pelamar?

\subsection{Tujuan}

a. Membangun database dan sistem informasi berbasis website untuk penerimaan karyawan baru

b. Menyediakan tampilan website yang bersahabat bagi pengguna sehingga mudah dalam penggunaan website.

c. Memberikan keefektifan dan efisien waktu dalam penerimaan karyawan baru

\section{KAJIAN PUSTAKA}

\subsection{Sistem}

Sistem seperangkat elemen yang membentuk kegiatan suatu prosedur atau bagan pengolahan yang mencari suatu tujuan atau tujuan-tujuan bersama dengan mengoperasikan data dan atau barang pada waktu rujukan tertentu untuk menghasilkan informasi dan atau energi atau barang[7].

\subsection{Website}

Menurut Puspitosari dalam [8] mengemukakan bahwa website adalah halaman informasi yang disediakan melalui jalur internal sehingga bisa diakses di seluruh dunia, selama terkoneksi dengan jaringan internet". Baik yang bersifat statis maupun dinamis yang membentuk satu rangkaian bangunan yang saling terkait, yang masing-masing dihubungkan dalam jaringan-jaringan halaman.

\subsection{Internet}

"internet adalah jaringan atau sistem pada jaringan komputer yang saling berhubungan dengan menggunakan sistem global transmission control protocol atau internet protocol suite (TCP/IP) sebagai protokol pertukaran paket untuk melayani miliaran pengguna diseluruh dunia"[9].

\subsection{PhpMyadmin}

PhpMyAdmin merupakan aplikasi web PHP sebagai administrator MySQL, PhpMyAdmin mendukung berbagai aktivitas $M y S q l$ seperti pengolahan data, table, relasi antar table dan sebagainya[10].

\subsection{MYSQL}

Dalam mengolah basis data (database) perangkat lunak yang sering digunakan ialah MySQL (My Structure Query Language), dimana MySQL (My Structure Query Language) adalah "suatu RDBMS (Relational Database Management System) yaitu aplikasi sistem yang menjalankan fungsi pengolahan data"[11].

\subsection{Waterfall}

"Model air terjun menyediakan pendekatan alur hidup perangkat lunak secara sekuensial atau terurut dimulai dari analisis, desain pengodean, pengujian dan tahap pendukung (support)"[12]. 


\section{ANALISA DAN PERANCANGAN}

\subsection{Analisa Sistem Berjalan}

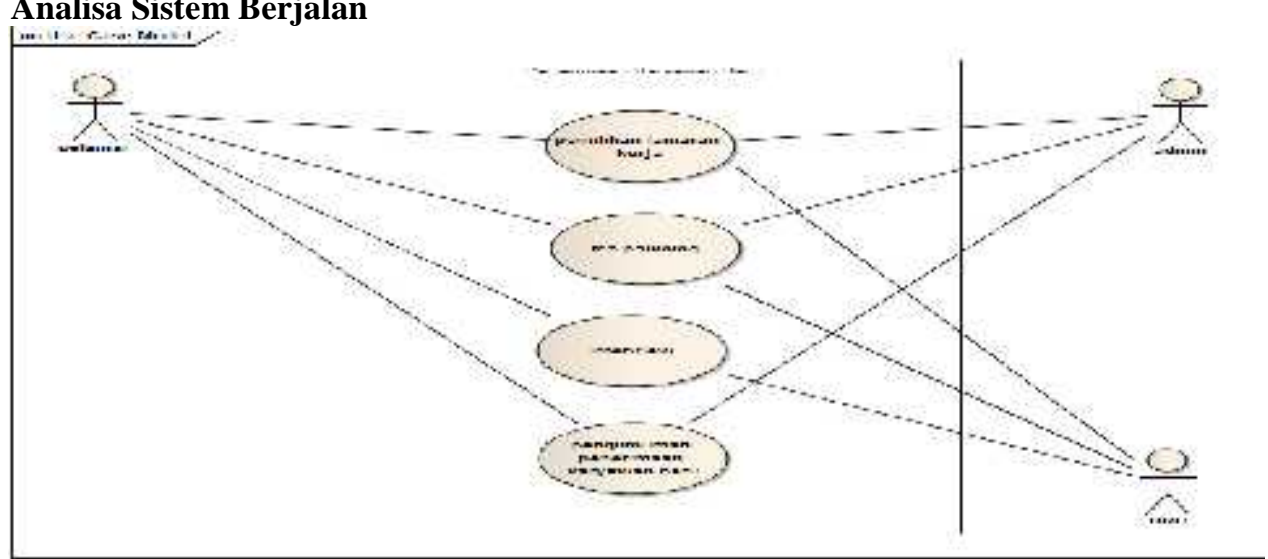

Gambar 1. Use Case Sistem Berjalan PT. Samyang Tour \& Travel

\subsection{Tahapan Perancangan Sistem Usulan}

Rancangan sistem usulan ini tentang proses penerimaan karyawan baru yang merupakan perkembangan dari sistem yang sedang berjalan pada PT. Samyang Tour \& Travel. Sistem yang dirancang mempunyai tahapan alur sistem yang hampir sama dengan sistem sebelumnya, namun ada beberapa perubahan tahapan karena sistem yang dirancang bersifat komputerisasi. Adapun uraian dari tahapan rancangan sistem usulan terbagi menjadi analisis kebutuhan, rancangan diagram use case, rancangan diagram aktivitas, rancangan dokumen sistem usulan dan rancangan prototype.

\subsubsection{Analisis Kebutuhan}

Dalam penyediaan informasi sebagai pendukung suatu laporan penerimaan karyawan baru membutuhkan waktu yang cukup lama dalam pengolahan datanya. Oleh karena itu dibutuhkan suatu sistem informasi yang terkomputerisasi, yang akan mengurangi kendala-kendala yang terjadi, sehingga akan mempermudah atau mempercepat rutinitas dalam proses penerimaan karyawan baru. Dalam Analisa kebutuhan terdapat 2 user yaitu admin dan pengguna. Untuk kebutuhan admin antara lain : login, mengelola tes akademik, mengelola data pelamar, dan laporan. Sedangkan kebutuhan pengguna antara lain melihat beranda, daftar akun, login, mengisi data pelamar, mengikuti tes online, mengirim pesan bantuan, melihat hasil pengumuman pelamar.

\subsubsection{Rancangan UML}

\section{Use Case Diagram}

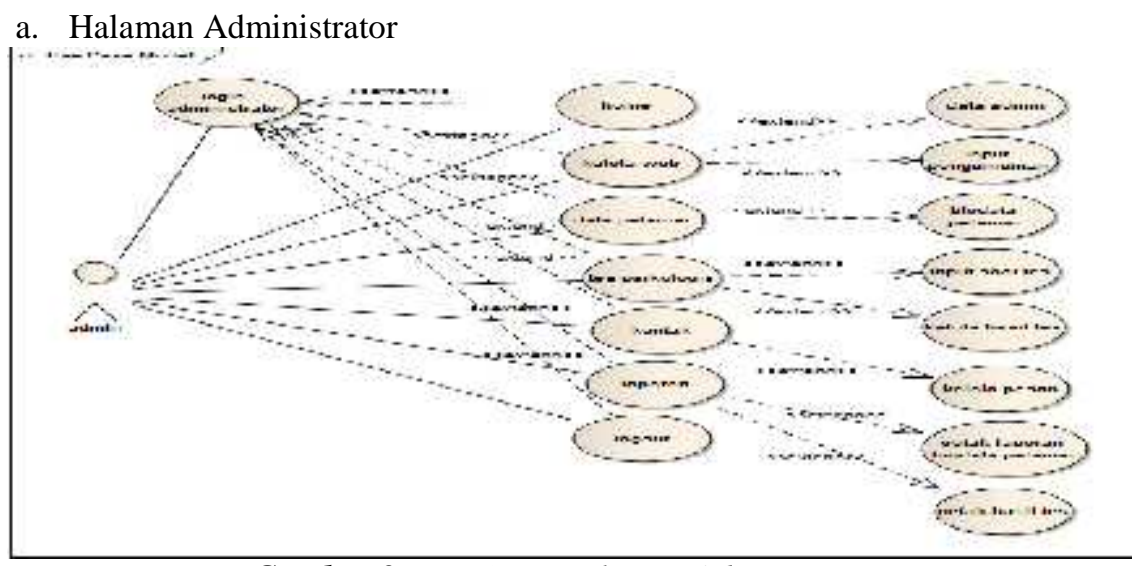

Gambar 2. Use Case Halaman Administrator 
b. Halaman Pelamar

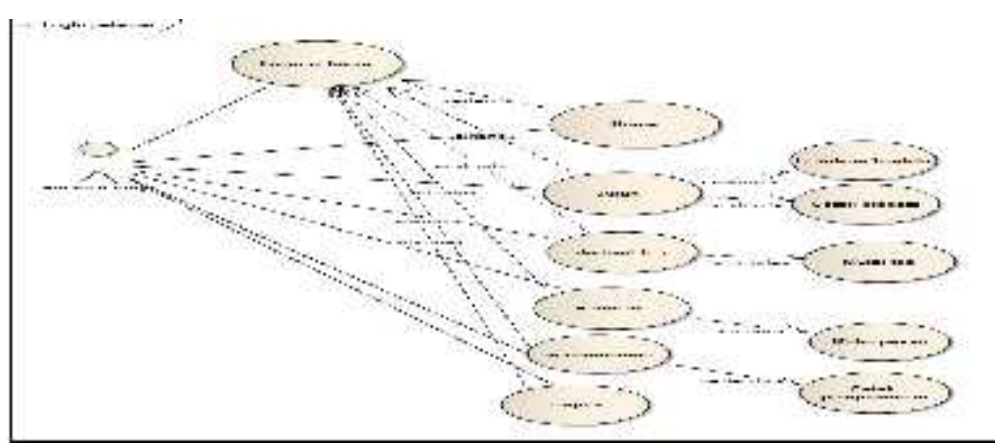

Gambar 3. Use Case Halaman Pelamar

\section{Activity Diagram}

a. Activity Diagram Login Administrator

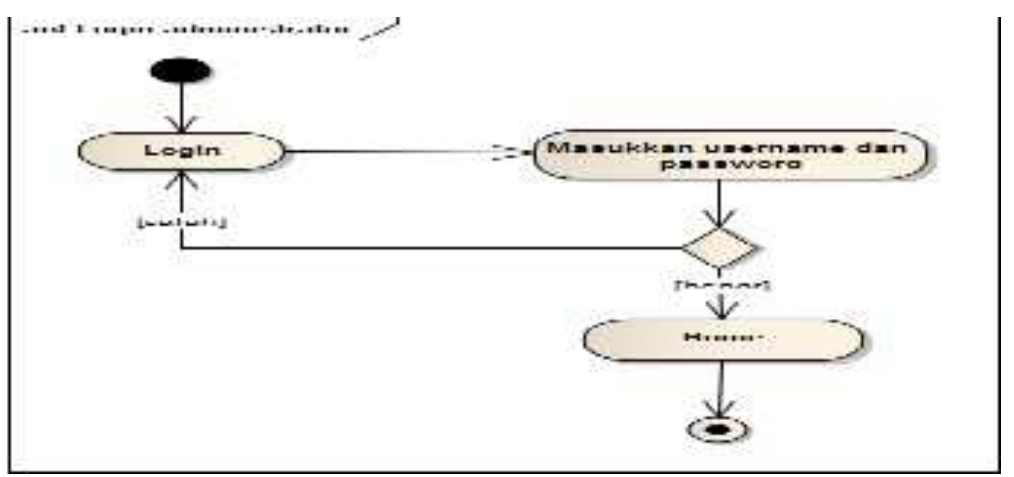

Gambar 4. Activity Diagram Login Administrator

b. Activity Diagram Kelola Web

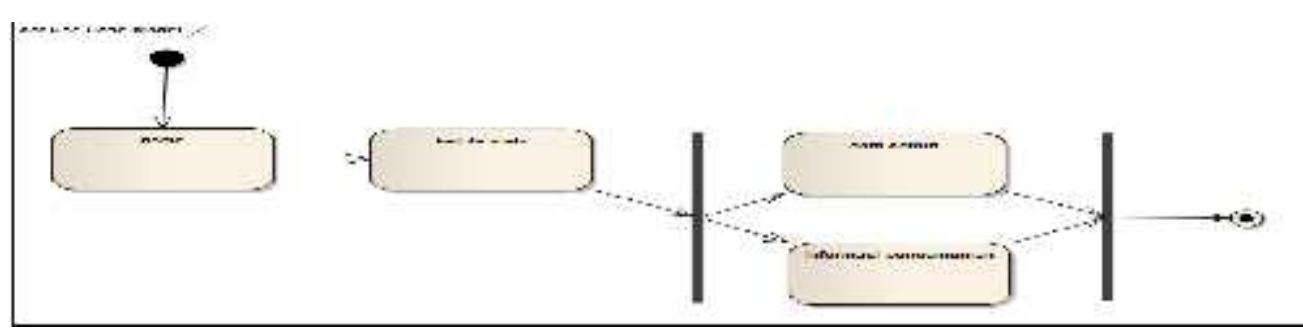

Gambar 5. Activity Diagram Kelola Web

c. Activity Diagram Kelola Tes

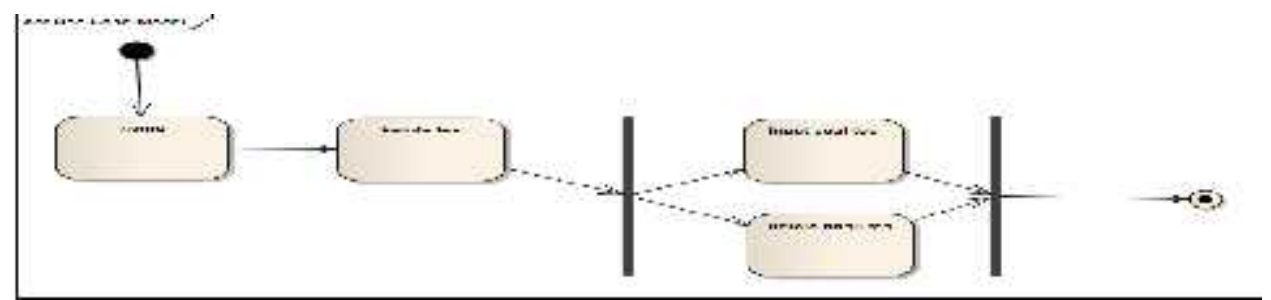

Gambar 6. Activity Diagram Kelola Tes 
JURNAL DIGIT Vol. 9, No.1 Mei 2019, pp.132 142

d. Activity Diagram Kelola Laporan

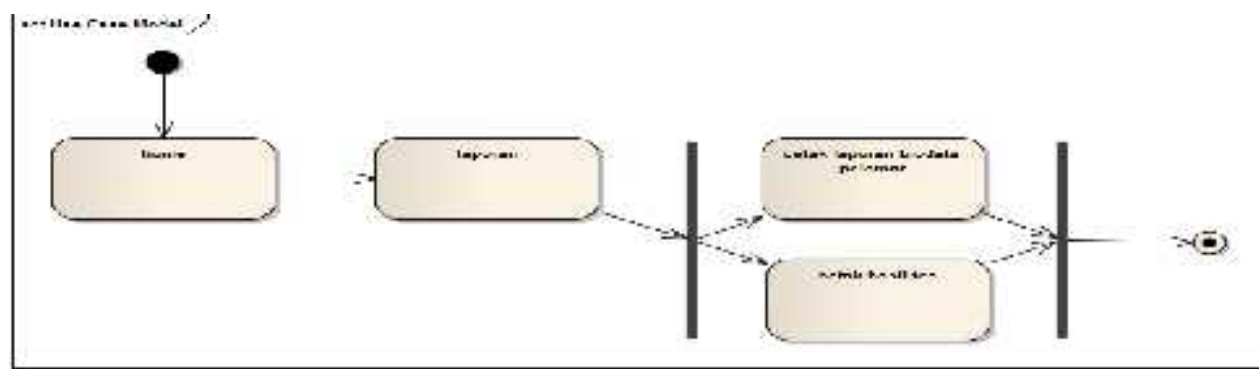

Gambar 7. Activity Diagram Kelola Laporan

e. Activity Diagram Akun Pelamar

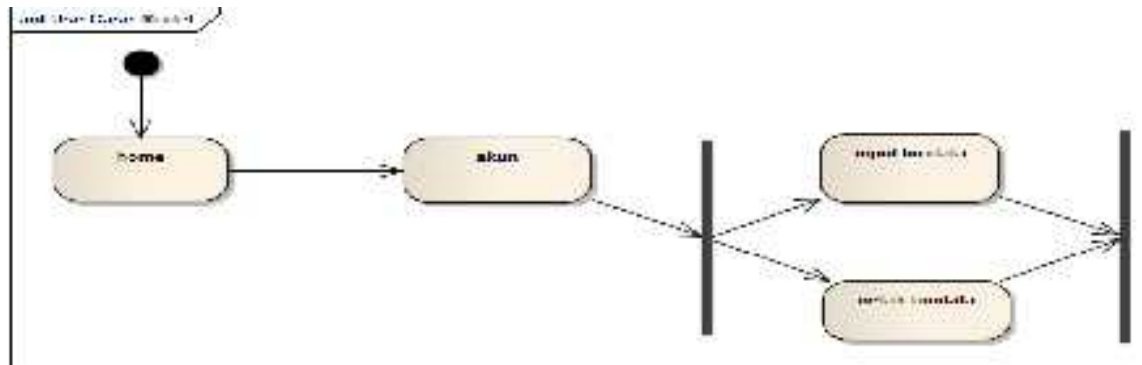

Gambar 8. Activity Diagram Akun Pelamar

f. Activity Diagram Jadwal Tes

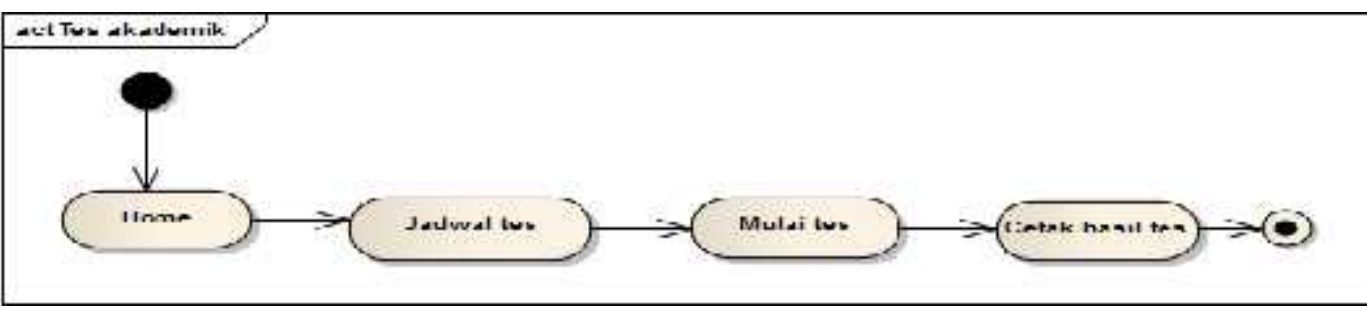

Gambar 9. Activity Diagram Jadwal Tes

g. Class Diagram

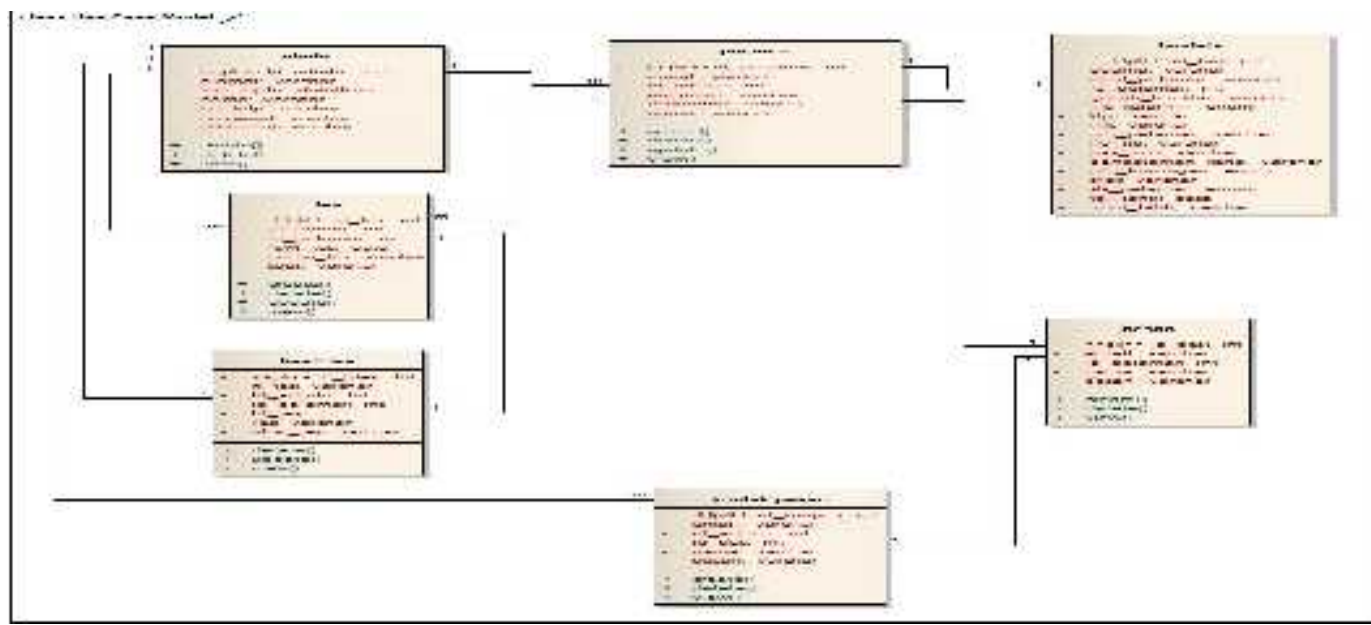

Gambar 10. Class Diagram 


\section{Sequence Diagram}

a. Sequence Diagram Daftar Akun Pelamar

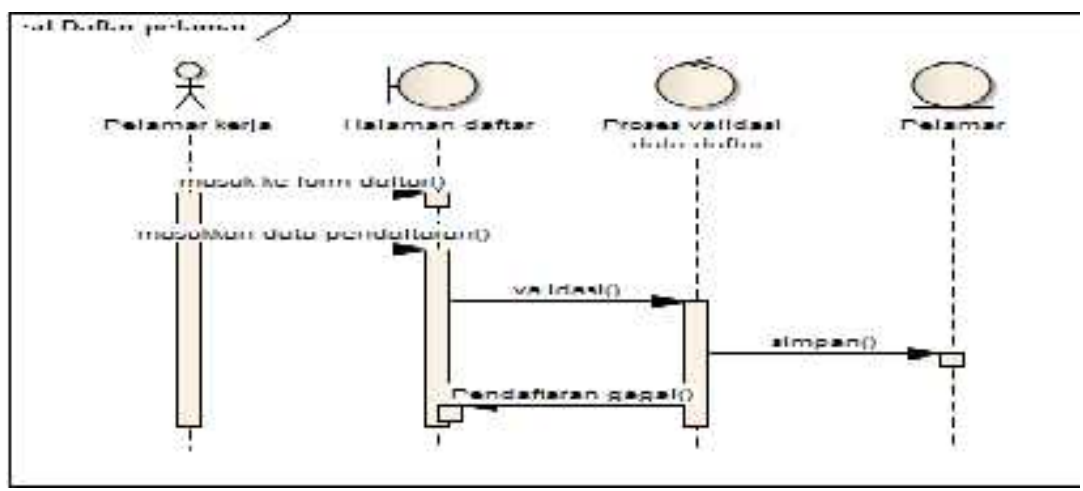

Gambar 11. Sequence Diagram Daftar Akun Pelamar

b. Sequence Diagram Login Pelamar

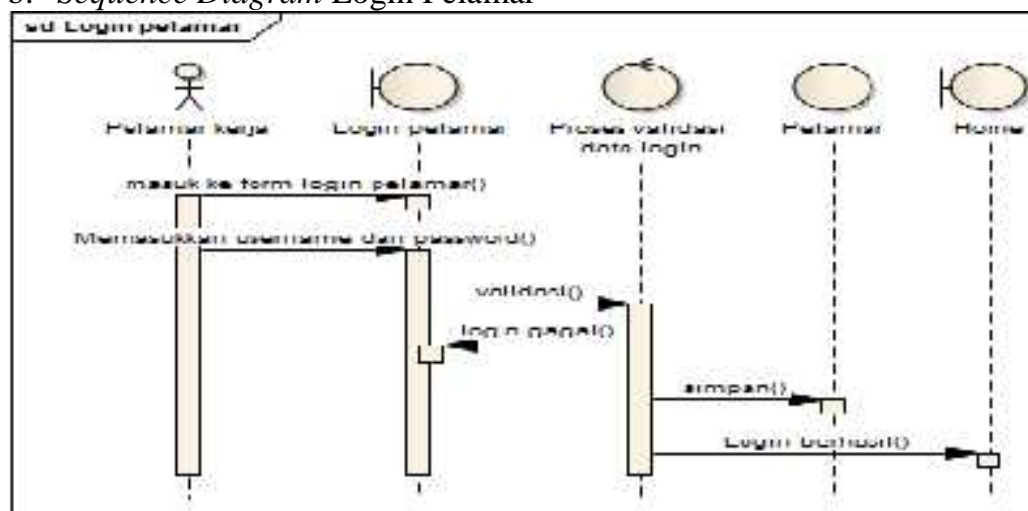

Gambar 12. Sequence Diagram Login Pelamar

c. Sequence Diagram Jadwal Tes

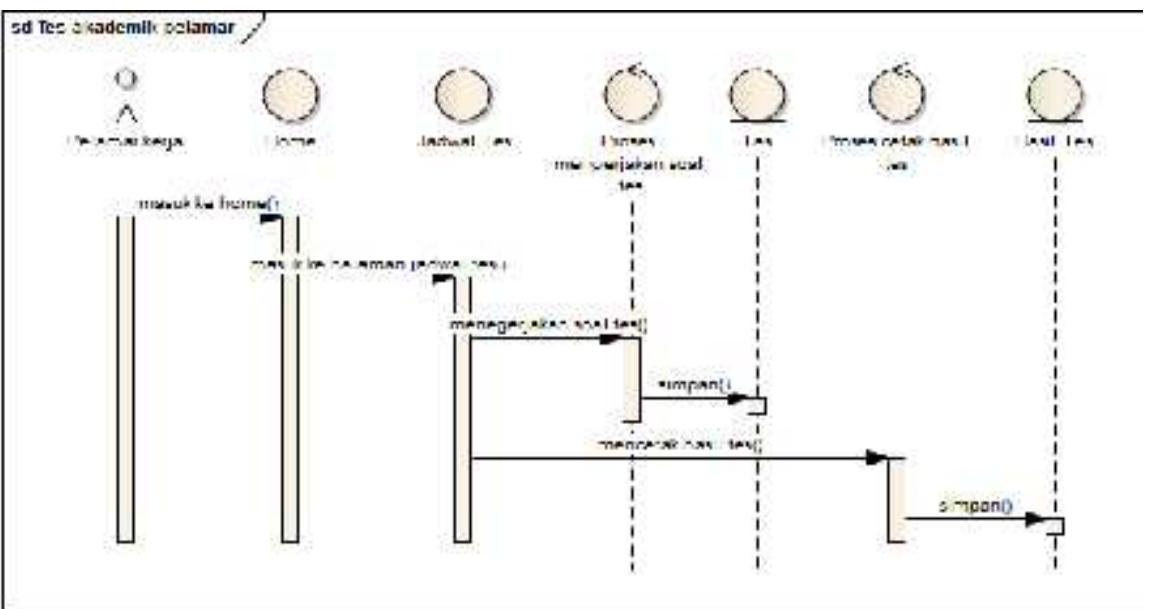

Gambar 13. Sequence Diagram Jadwal Tes 
JURNAL DIGIT Vol. 9, No.1 Mei 2019, pp.132 142

d. Sequence Diagram Kelola Tes

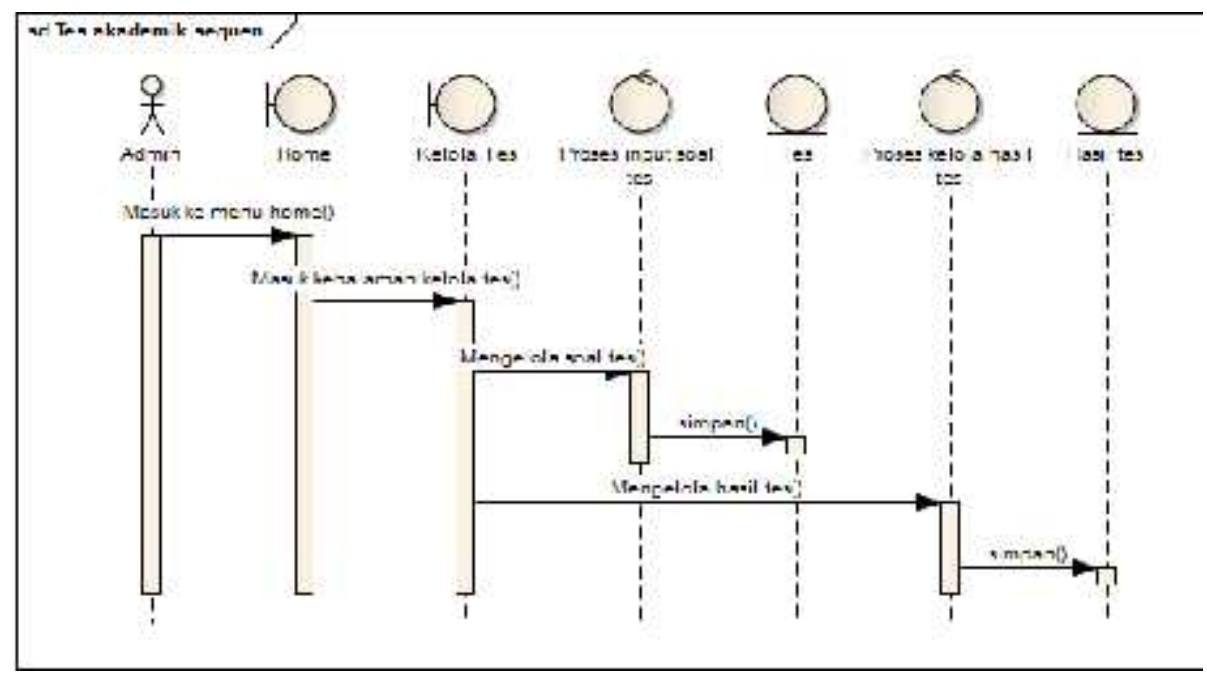

Gambar 14. Sequence Diagram Kelola Tes

e. Class Diagram

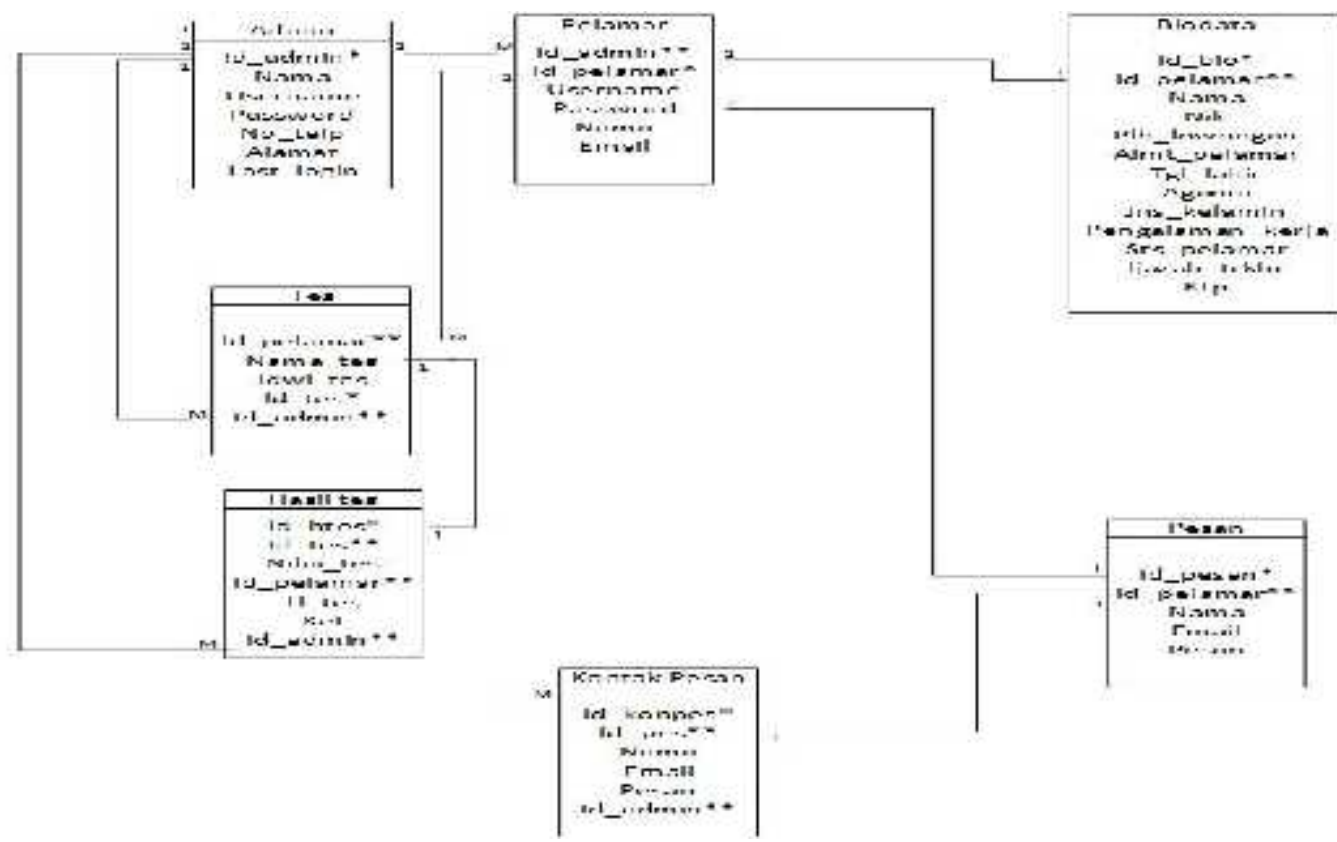

Gambar 15. Logical Record Structure (LRS)

Spesifikasi File

a. Spesifikasi file admin

Tabel 1. Spesifikasi File Admin

\begin{tabular}{lllccc}
\hline No & \multicolumn{1}{c}{ Elemen data } & \multicolumn{1}{c}{ Nama Field } & Tipe & Size & \multicolumn{1}{c}{ Keterangan } \\
\hline 1. & IdAdmin & Id_admin & Int & 11 & Primary Key \\
\hline 2. & Nama Admin & Nama & Varchar & 30 & \\
\hline
\end{tabular}




\begin{tabular}{lllll}
\hline 3. & Username login & Username & Varchar & 20 \\
\hline 4. & Password login & Password & Varchar & 20 \\
\hline 4. & Nomer telphone & No_telp & Varchar & 15 \\
\hline 5. & Alamat admin & Alamat & Varchar & 50 \\
\hline 6. & Terakhir Login & Last_login & Datetime & - \\
\hline
\end{tabular}

b. Spesifikasi file pelamar

Tabel 2. Spesifikasi File Pelamar

\begin{tabular}{lllccc}
\hline No & \multicolumn{1}{c}{ Elemen data } & \multicolumn{1}{c}{ Nama Field } & Tipe & Size & Keterangan \\
\hline 1. & IdPelamar & Id_pelamar & Int & 11 & Primary Key \\
\hline 2. & Username login & Username & Varchar & 10 & \\
\hline 3. & Password login & Password & Varchar & 20 & \\
\hline 4. & Nama pelamar & Nama & Varchar & 50 & \\
\hline 5. & Email & Email & Varchar & 50 & \\
\hline 6. & Id admin & Id_admin & Int & 11 & Foreign key \\
\hline
\end{tabular}

c. Spesifikasi file biodata

Tabel 3. Spesifikasi File Biodata

\begin{tabular}{|c|c|c|c|c|c|}
\hline No & Elemen data & Nama Field & Tipe & Size & Keterangan \\
\hline 1. & Id biodata & Id_bio & Int & 11 & Primary Key \\
\hline 2. & Id pelamar & Id_pelamar & Int & 11 & Foreign Key \\
\hline 3. & Nama pelamar & Nm_pelamar & Varchar & 50 & \\
\hline 4. & Nomer nik & Nik & Varchar & 20 & \\
\hline 5. & Pilih lowongan & Plh_lowongan & Enum & & \\
\hline 6. & Alamat pelamar & Almt_pelamar & Varchar & 50 & \\
\hline 7. & Tanggal lahir & Tgl_lahir & Date & & \\
\hline 8. & Tempat lahir & Tmpt_lahir & Varchar & 20 & \\
\hline 9. & Agama & Agama & Enum & & \\
\hline 10. & Jenis kelamin & Jns_kelamin & Enum & & \\
\hline 11. & Nomer Telephone & No_tlp & Varchar & 15 & \\
\hline 12. & Status Pelamar & Sts_pelamar & Enum & & \\
\hline 13. & Pengalaman kerja & Pengalaman_kerja & Varchar & 100 & \\
\hline 13. & Ijazah Terakhir & Ijazah_terakhir & Varchar & 20 & \\
\hline 14. & Pas foto & Pas_foto & Varchar & 20 & \\
\hline 15. & KTP & Ktp & Varchar & 20 & \\
\hline 16. & SKCK & Skck & Varchar & 20 & \\
\hline
\end{tabular}

d. Spesifikasi file tes

Tabel 4. Spesifikasi File Tes

\begin{tabular}{lllccc}
\hline No & Elemen data & \multicolumn{1}{c}{ Nama Field } & Tipe & Size & Keterangan \\
\hline 1. & IdTes & Id_tes & Int & 11 & Primary Key \\
\hline 2. & Nama Tes & Nama_tes & Varchar & 30 & \\
\hline 3. & Jadwal Tes & Jdwl_tes & Date & & \\
\hline 4. & Soal tes & Soal_tes & Varchar & 500 & \\
\hline
\end{tabular}


JURNAL DIGIT Vol. 9, No.1 Mei 2019, pp.132 142

\begin{tabular}{llllll}
\hline 5. & Id Pelamar & Id_pelamar & Int & 11 & Foreign key \\
\hline 6. & Id Admin & Id_admin & Int & 11 & Foreign key \\
\hline
\end{tabular}

e. Spesifikasi file hasil tes

Tabel 5. Spesifikasi File Hasil Tes

\begin{tabular}{llllll}
\hline No & \multicolumn{1}{c}{ Elemen data } & Nama Field & Tipe & Size & Keterangan \\
\hline 1. & Id Hasil Tes & Id_htes & Int & 11 & Primary Key \\
\hline 2. & Id Tes & id_tes & Int & 11 & Foreign key \\
\hline 3. & Nilai Tes & Nilai_tes & Varchar & 20 & \\
\hline 4. & Id Pelamar & Id_pelamar & Int & 11 & Foreign $k e y$ \\
\hline 5. & Hasil Keseluruhan & H_kes & Varchar & 30 & \\
\hline 5. & Keterangan & Ket & Enum & & \\
\hline 6. & Id Admin & Id_admin & Int & 11 & Foreign key \\
\hline
\end{tabular}

\section{HASIL DAN PEMBAHASAN}

\subsection{Tampilan Home Penerimaan Karyawan Baru}

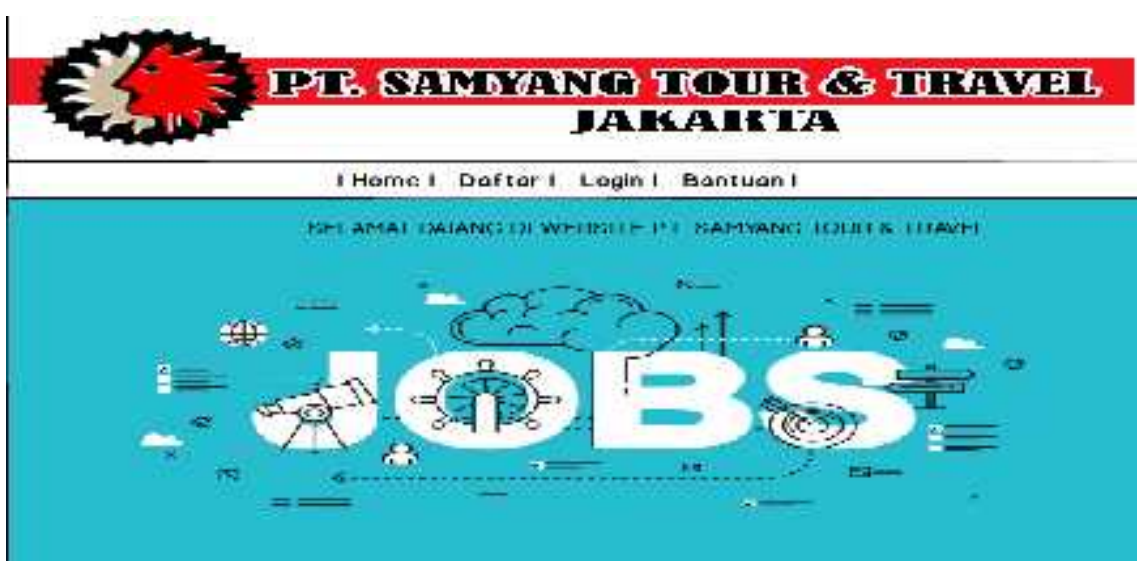

Gambar 17. Home Penerimaan Karyawan Baru

4.2 Tampilan Login Administrator

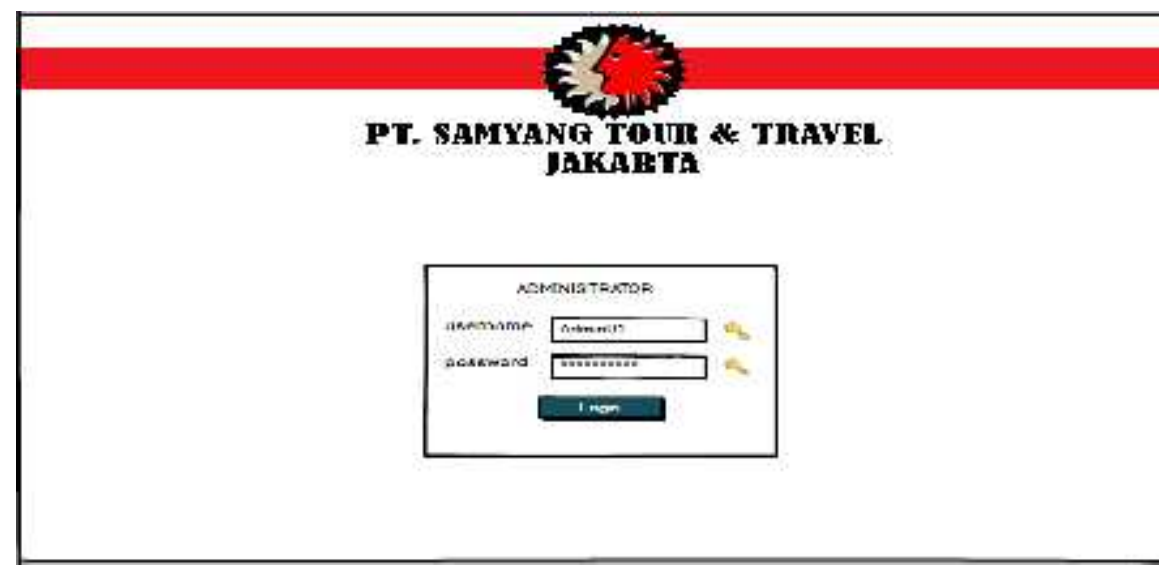

Gambar 18. Login Administrator 
4.3 Tampilan Kelola Web

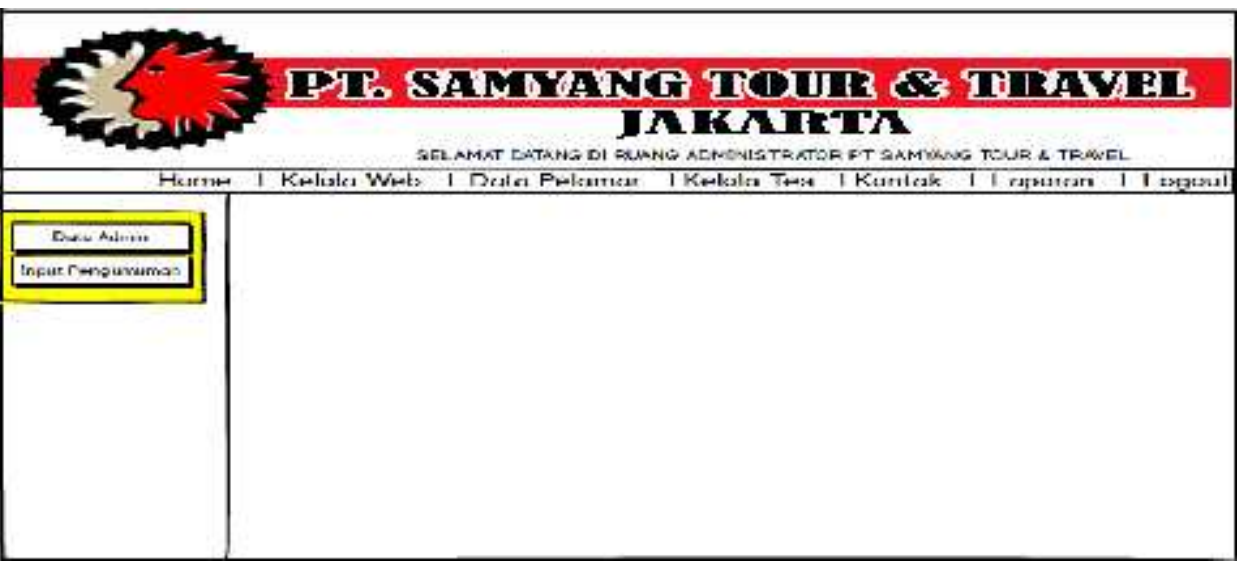

4.4

Tampilan Jadwal Tes

Gambar 19. Kelola Web

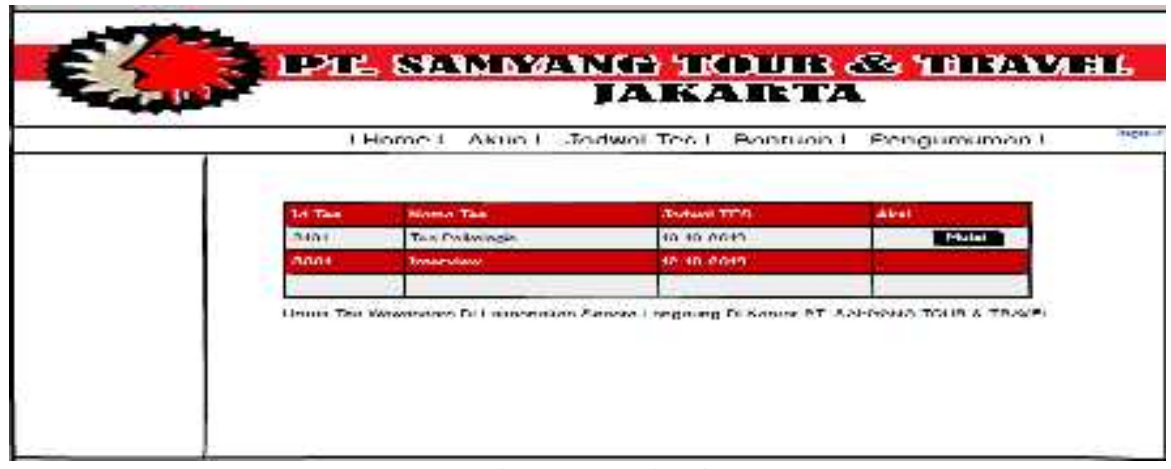

Gambar 20. Jadwal tes

\section{KESIMPULAN DAN SARAN}

\subsection{Kesimpulan}

Berdasarkan pembahasan yang telah dilakukan terhadap perancangan sistem penerimaan karyawan baru berbasis website pada PT. Samyang Tour \& Travel, maka dapat diambil suatu kesimpulan sebagai berikut :

1. Semua hasil proses yang dilakukan pada tahap perancangan telah dicapai.

2. Sistem informasi penerimaan karyawan baru diharapkan dapat memberikan kemudahan kemudahan dalam pekerjaan bagi PT. Samyang Tour \& Travel Jakarta baik dari segi waktu, biaya dan efesiensi kerja.

3. Sistem informasi penerimaan karyawan baru ini dapat dikembangkan dikemudian hari dan diupdate.

\subsection{Saran}

Adapun saran saran yang ingin disampaikan yaitu:

1. Dalam periode tertentu perusahaan perlu melakukan update perangkat komputer dan software yang digunakan.

2. Sistem informasi penerimaan karyawan baru berbasis website pada PT. Samyang Tour \& Travel Jakarta ini perlu dikembangkan. 


\section{DAFTAR PUSTAKA}

[1] Putri, D. A. Penerapan Metode Fuzzy Saw Sebagai Pendukung Keputusan Pengangkatan Karyawan Tetap Perusahaan. 2018;15(1), 31-36.

[2] Handayani, R. I., \& Muzakir, A. Sistem Pendukung Keputusan Penerimaan Karyawan Dengan Menggunakan Metode Analytical Hierarchy Process (Ahp) Studi Kasus: Pt. Virtus Venturama. Jurnal Pilar Nusa Mandiri, 2018; 14(1), 43-48.

[3] Ayuni, \& Baidawi, T. Analisis Penerimaan Karyawan Posisi Field Collector Menggunakan Algoritma C4.5 . 2017;2(2), 1-6.

[4] Pradipti, T. F. SNIPTEK 2016 Perancangan Sistem E-Recruitment Berbasis Web Pada Pt . Agung Podomoro Land Tbk Jakarta. 2016;141-146.

[5] Safitri, M. aldhila. astrid. Sistem Informasi Lowongan Kerja Berbasis Web. 2018, 14(1), 1.

[6] Puspitasari, D. Rancang Bangun Sistem Informasi Koperasi Simpan Pinjam Karyawan Berbasis Web. Jurnal Pilar Nusa Mandiri, 2016;11(2), 186-196.

[7] Djahir, Y., \& Pratita, D. Bahan Ajar Sistem Informasi Manajemen. Yogyakarta: Deeppublish. 2015

[8] Handayani, V., Wijianto, R., \& Anggoro, A. Sistem Informasi Pendaftaran Seleksi Kerja Berbasis Web Pada Bkk ( Bursa Kerja Khusus ) Tunas Insan Karya Smk Negeri 2. 2018;6(1), 76-84.

[9] Anhar. Panduan Bijak Belajar Internet Untuk Anak. Yogyakarta: Google Playbook.2016.

[10] Rahman, S. Bengkel Web Dan SEO Joomla. jakarta: PT Elex Media Komputindo.2013.

[11] Sibero, A. Web Programming Power Pack. Yogyakarta: Mediakom.2013.

[12] Rosa, A., \& Shalahuddin, M. Kolaborasi Rekayasa Perangkat Lunak Terstruktur dan Berorientasi Objek. Bandung: Informatika.2016. 